\title{
MESSAGE PROTOTYPE FOR TRANSMISSION OF A CDA WITH THE STANDARD HL7 FOR A TELEDIAGNOSTIC AND TELECONSULTATION SYSTEM
}

\author{
LILIA E. APARICIO P, JAIME A. BENÍTEZ \& MIGUEL A. ÁVILA A \\ Engineering Faculty, Universidad Distrital Francisco José de Caldas, Bogotá, Colombia
}

Received: Jun 08, 2020; Accepted: Jun 28, 2020; Published: Sep 19, 2020; Paper Id.: IJMPERDJUN20201340

\section{INTRODUCTION}

In the theoretical framework of the investigation for the development of the worldwide telemedicine, it exits the HL7 standard, that correspond to one of the lineament of the global integration of the infrastructure need for the offer of services in telemedicine, in an environment of integration and interoperability of information systems, that along the technological development has given results that today are seen in production of the different Colombian institutions and multiple no integrable information systems.

For the Colombian case, it is important the development of the messenger service for each one of the components of a health management system, where each of them has a considerable complexity, for that reason it is necessary to purpose a macro project that allows the integration of plenty works, where each of them correspond to a subgroup of messages and for its development its necessary to appropriate the reference and the definition of the identifiers of the standard adapted to Colombia.

On this work, the objective was grounded in the development of the construction methodology of a messaging prototype for the transference of one CDA (Clinical Document Architecture) which will be integrated in the standardization system of teleconsultation, applied to the Colombian case, which is part of the macro project HL7 of teleconsultation and telediagnostic, that it is being constructed for several organizations, such as 
FUNTELMED, according to the current regulations, legalization of consultation services and diagnostic, in this moment already regulated in the area of health of Colombia, and for identities like the Ministry of social protection and the regimentation for telemedicine services.

In the actual health care organizations, they exist different systems for the management of clinical information; some of them with specific characteristics depending on the area for which they were develop, for example: Registration System, admissions, laboratory, radiology, etc. In most of the cases, there is not allowed to share, or exchange data with other applications, it generates among other things delays on the process of attending the patients and so it increase the cost of the service. On the other hand, the Colombian government's policies frame a high investment to offer the telemedicine services, nevertheless, according to the investigation made, there is no evidence of clear technological products, which means standardized, that allows in first place making a global technology transfer, and in second place integrate the resources that nowadays every single hospital of the country -public or private has. Additional, the standardization for the telemedicine is new for the country, so for example the HL7 can be the one call for the solution or the problems related with the resource integration.

All the above justify the emerge of the question; How can it be developed one message for the transmission of CDA's so it can be integrated to one standardization system HL7, that contains interfaces that facilitated the integration of different transmission applications of CDA's existing in the various and different institutions of health in Colombia, with the final propose of allowing the interoperability between information systems?

Therefore, the objective of this investigation is to create a message prototype for the transfer of one CDA, using the standard HL7 that can hold the interoperability between applications of the health management in telemedicine and teleconsultation services.

\section{INVESTIGATION METHODOLOGY}

The methodology developed for this project according to the objectives already exposed, and base on the methodology of the Software Engineering of prototyping, is the following:

- Phase 1: Specification and analysis.

Detail exploration of the HL7 standard.

Basic design of the prototype.

- Phase 2: Design and construction.

Direct work with the HL7 messaging scheme according with the Colombian case, in accordance with the descriptions of the ballot and the CDAs.

Construction of the initial prototype.

- Phase 3: Evaluation.

Validation proof of the message from the prototype.

- Phase 4: Modification.

According with the validation proof of the message from the prototype. 
- Phase 5: Technical Design.

Detailed design.

Redesign of the prototype.

Document elaboration respective and prototype of the implementation guide.

- Phase 6: Proof and programming.

Validation is made, according with the prototype message, in relation with the initial phase of the technical design.

Final Documentation.

\section{STRUCTURE OF THE RESEARCH WORK}

On the structure of the research work (Shape 1) it can be identify stages that was stablish and develop in order to reach the objectives raised having as a initial stage the revise of the actual standard of Colombia and its respective background; in the following there is proceed to make an identification of the necessities for the establishment of the unsolved problem; after that there is use a scientific material; and then there is made and designed and construction proposal for the message according to the identified areas, with the final purpose of integrated to the standard establish, realizing a prototype of this, that will be prove on a real scenery. Finally, this will throw a technological result as an input of the migration of the actual estate to the establish HL7 standard.

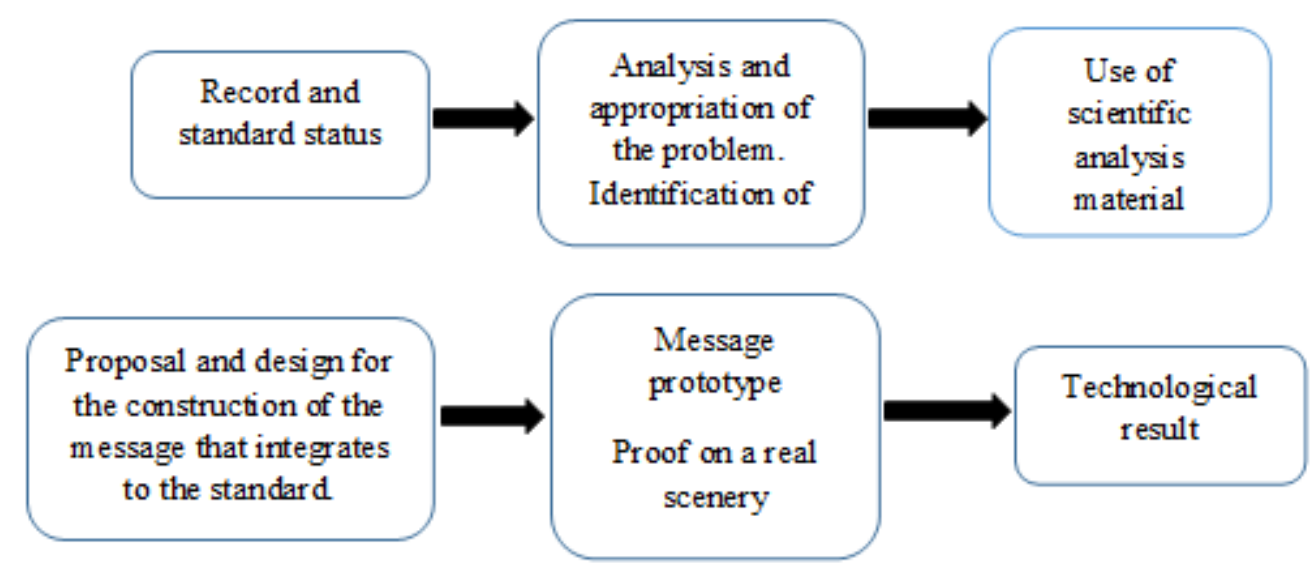

Figure 1: Structure of the Research Work.

In order to share data with the different systems there is necessary to count with the a common language, that allows the sharing of information with other systems being the HL7 a set of protocols for the interchange of clinical information that allows the functional interoperability, which means the ability of physical communication between too systems for the exchange of information without errors and semantic interoperability, that means common language in so far as name, grammatical structure, interpretation ability and well use of the exchange information.

The HL7 considers four principal specifications, which are the messenger and the workflow, documents or CDA's, context or CCOW and the language for the support of decision-making [1]. 
The CDA (Clinical Document Architecture) defines the semantic and syntactic rules for the language of expression, of the clinical documents resultants of any process and procedure in the health area that requires being interchange or storage looking forwarded to stablish the electronical medical history of the patient

The CCWO its and standard, orientated to the final user that facilitates the integration of applications and improvements of the experiences of them.

One if the principal challenges that the health organization face, is the generations of some necessities, the impact over the security, the effectiveness and the cost; for not having the right information in the opportune moment. The necessities of counting with this heterogeneous information of the medical attention point, the increase on the cost for the transference of paper registers that are need on this era of the electronic commerce.

Most of these challenges derive of the incapacity of share and administrate data in and between organizations. These challenges can be overcome only if the organizations follow common standards adjusting their information systems to allow the sharing of data [2].

The specifications for the HL7 messaging includes:

- $\quad$ Structure for the interchange of data.

- Interactions definition and interchange protocols.

- Codifications (Control vocabulary).

- $\quad$ Specifications on use.

The specifications of messaging transportation (the movements of the information since the transmitter to the receptor) are no develop for the HL7. Nevertheless, the ballot HL7 V3 includes the reference documentation about 3 principal specifications: ebXML (HTTP, SMTP y TCP/IP) SOAP - Web Services MLLP (Minimum Lower Layer Protocol).

The first information system of the SNS (National System of Health) was the SIS (Information System of Health), a system highly oriented to the statistical aspects of the clinical organizations, based on the register systems of clinical assistance. Those data were digitalized consolidated and remitted for territorial entities. After the law 100 of 1993 implementation, the country started a transformation of their health system which the startup of the General System of Social Security (SGSSS), and according to this was the appearance of the SIIS (Integral System of Health Information), which in the begging was orientated to the reassurance process of information for the EPS, and the billing services of the IPS [3].

Into this context, a group of universities, as providers of technology and health service providers, conformed in 2007, what will be the gestor group of the HL7 Colombia, considering the challenges that the country was facing in the evolution of the informatics necessities for the health sector [4].

The pilot system of the telemedicine includes platforms of software, hardware and data prosecution, that supports through a safe tele-communication red, tele-consultation services, tele-diagnostic, second medical opinion, reference and counter reference of patients for cases of specialized medicine, to be implemented in administration agreement with entities and institutions providers of public and private health (ARS,IPS,EPS, ESS) linked to the micro-reds of Bogota and 
Cundimarca Health, initial in a rural level, and then to a urban level that can be modulated and scale to be in a national level and that can scale too to systems of medical continuous tele-education and permanent public information.

In addition, the Project purpose an administration agreement of cooperation with the center of formation for human talent for health in Sena, Bogota Regional, for the development of a line of professional formation, and capacitation for working in the telesalud area [5].

The HL7 promote the use of their standard, in the health organizations for increasing the effectiveness and the efficacy in the different involved process for the health attention and for everyone benefits. The HL7 standard is one of the most implemented in the United States. More than 2.400 members that represent 500 organization, that includes a $90 \%$ of the biggest companies of informatics technology applied in a health environment [6].

The analysis of the evolution of the HL7 standard, allows the identification of a set of clue aspects not just for a standard, but also for all the standards of electronic interoperability of data [7].

On the other hand, the interoperability is defined as "The ability of 2 or more systems - or components- for exchange information and use the information that has been exchange" [8].

The exchange of information is more known as the operative interoperability or functional interoperability, while the property of using transfer information is define as semantic interoperability.

To integrate different systems of information from a patient, there is need of transfer information from another system. This transfer in general is made through adaptable and personalize interfaces.

Another concept that is important to consider is the XML, which is a language of extensible label too simple, but strict that plays a fundamental role in the exchange of a big variety of data. Is a language like the HTML, but its main function is to describe data and not to show it like the HTML. The XML format allows the lecture of data through different applications.

The XML technologies are a set of modules that offer useful services to the demands that are more frequent to the users. XML serves for structuring, storing and exchanging information [9].

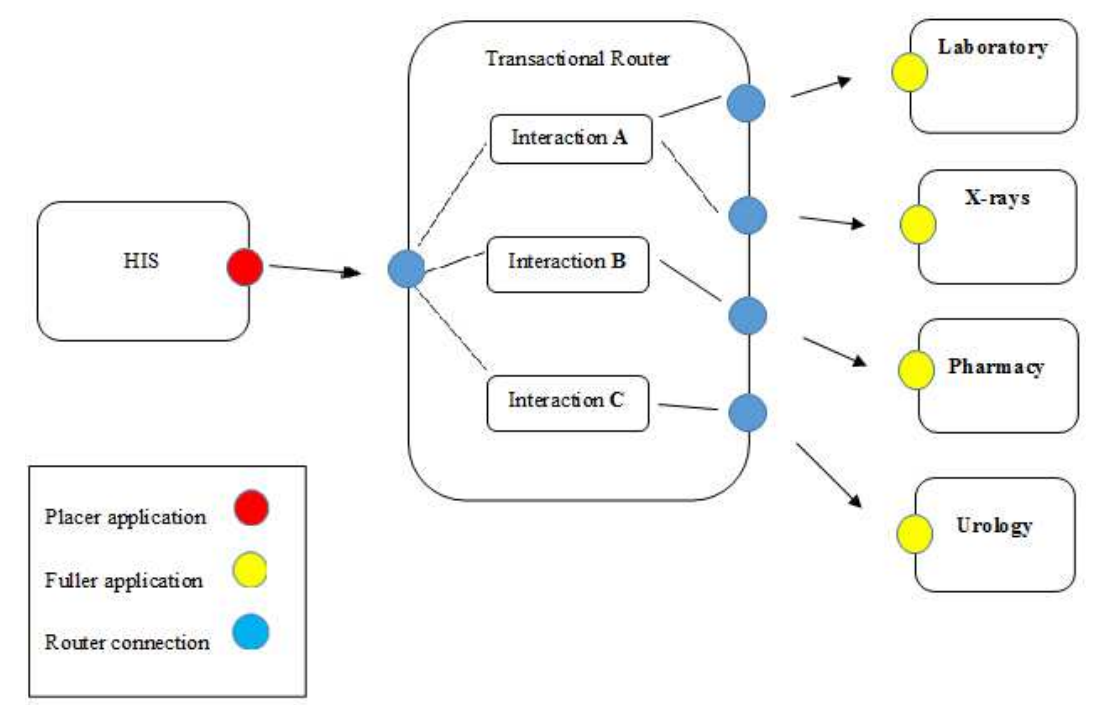

Figure 2: XML Tecnologies. 
The diversity of information clinical systems, that are manage force the exist of the integration of application with standards such as the HL7, to guarantee the interoperability, and in that way, increment the quality of service and attention provided to the patient.

The HL7 works within various standards, being the messenger and the CDS, the most known and applied in a global scale. For this specific case, will work with messenger because most of the hospitals count internally with various intercommunicated systems that can be solved identifying the scenarios where it is necessary the exchange of information within the application of HL7 messenger, to give a solution for the interoperability problem.

In the case of the transmission of the CDA's, it is necessary to identify the parameters that regularized the transference, so it can be possible to share the information between specialists.

\section{PROTOTYPE OF MESSAGE FOR THE TRANSMISSION OF A CDA BETWEEN APPLICATIONS}

On the designs and development process for the message prototype for a transmission of a CDA, between application using the systemic approach, if must be considered the aspects that there are described below, this will allow the development of the transmission.

A generic framework to express supports the consultations in the version threes of the HL7 standard:

- The common consultation, has been used for applications that uses the HL7 standard

- New consultation that can be specified by a new case valid in the health information management. The intention with the HL7 standard is to make the establishment of the interactions in an easier way between heterogeneous applications.

The HL7 standard, include even the most common queries that they can be made. This is defined within a functional application domain, for example:

- Data correspond within one patient, for example, send all the laboratory results for the patient \#123456

- Data about various patients, for example, send the list of patients whose principal doctor is the Dr. \#123

- Data that is not related with the patient, for example, send the specific age for the normal values for the serum protein.

- Data over a specific Rank of time, for example, send all the results of glucose tests report in the period between 1 of January of 1998 to December 31 of 1999 for the patient \#123456

- Specification of the query message.

Structure of the payload of a compound message, HL7 V3, for a query specification consist on three parts:

- The HL7 transmission container.

- Control law

- Structure of parameters definition that specifies what is required for each query defined in a domain.

The definitions of the structure of the parameters are the content define for the committee of dominion for a query specification message. 
Query Response Message.

The structure of the useful load of one message compose of HL7 V3, consists on:

- The HL7 transmission container.

- The law of response control of the query.

- $\quad$ Message defined by the domain committee.

The law for the control response requires one attribute to identify the consultation session to which is associated the message of the consultation response.

\section{REQUIREMENTS}

Currently the FUNTELMED foundation, counts with the MARELY system, in which the is stored the clinical information of the patients that are catered, the system counts with the following chats in where they can be consult the required information for the implementation of the message.

Patient Chart (figure3): Contains the information of the patients Registered in the system belonging to a certain entity.

\begin{tabular}{|c|c|c|c|}
\hline \multicolumn{4}{|c|}{ Pacientes } \\
\hline & Nombre de columna & Tipo comprimido & Aceptación de valores NULL \\
\hline \multirow{16}{*}{8} & IdPaciente & int & No \\
\hline & IdEntidad & int & Sí \\
\hline & IdTipoIdentificacion & int & No \\
\hline & NumIdentificacion & varchar(50) & No \\
\hline & Nombre1 & varchar(100) & No \\
\hline & Nombre2 & $\operatorname{varchar}(100)$ & Sí \\
\hline & Apellido1 & $\operatorname{varchar}(100)$ & No \\
\hline & Apellido2 & $\operatorname{varchar}(100)$ & Sí \\
\hline & Sexo & varchar(1) & No \\
\hline & GrupoSanguineo & $\operatorname{varchar}(3)$ & No \\
\hline & $\mathrm{RH}$ & $\operatorname{varchar}(1)$ & Sí \\
\hline & LugarNacimiento & varchar(150) & Sí \\
\hline & FechaNacimiento & datetime & No \\
\hline & Telefono & $\operatorname{varchar}(50)$ & Sí \\
\hline & Celular & $\operatorname{varchar}(50)$ & Sí \\
\hline & Email & $\operatorname{varchar}(50)$ & Sí \\
\hline
\end{tabular}

Figure3: Pacients MARELY System.

Chart Info CDA (figure 2): Contains the information of the CDA documents created from the assessment made of the patients. 


\begin{tabular}{|c|c|c|c|}
\hline \multicolumn{4}{|c|}{ InfoCDA } \\
\hline & Nombre de columna & Tipo comprimido & Aceptación de valores NULL \\
\hline \multirow[t]{8}{*}{ ? } & IdCDA & int & No \\
\hline & ModuleID & int & Sí \\
\hline & IdPaciente & int & Sí \\
\hline & FechaGeneracion & datetime & Sí \\
\hline & Descripcion & varchar(150) & Sí \\
\hline & Archivo & $\operatorname{varchar}(50)$ & Sí \\
\hline & CreatedByuser & int & Sí \\
\hline & CreatedDate & datetime & Sí \\
\hline
\end{tabular}

Figure 2: Info CDA MARELY System.

The systems require the design and implementation of the HL7 Interfax, to allow the consultation of the clinical documents of the patients, based on the following searching criteria:

- $\quad$ Patient name.

- $\quad$ Patient identification number.

- Date range.

\section{ANALYSIS}

\section{Roles}

Fulfilling with the specification con the HL7, there was determine that they exist two roles on this message (Shape 3):

Consultation placement (Query Placer): Application responsible of fill the necessary parameters for the realization of the consult, and the control of the condition of it.

Consultant realization (Query Fulfiller): Application in charge of process the parameters corresponded to the message, and that create the respond of the consultation.

\section{Interactions}

Check search of CDA: (Find CDA Query): Information request with regard don a Clinical document.

Respond to a research consultant of a CDA: (Find CDA Query Response): Respond that contains the information of the clinical document that has been solicited

Script: The propose of this Script is to illustrate one consult for a Clinical Document (CDA) of one patient achieving with the search criteria

The purpose of this storyboard is to illustrate a query for Clinical Document (CDA) of a specifically patient. 


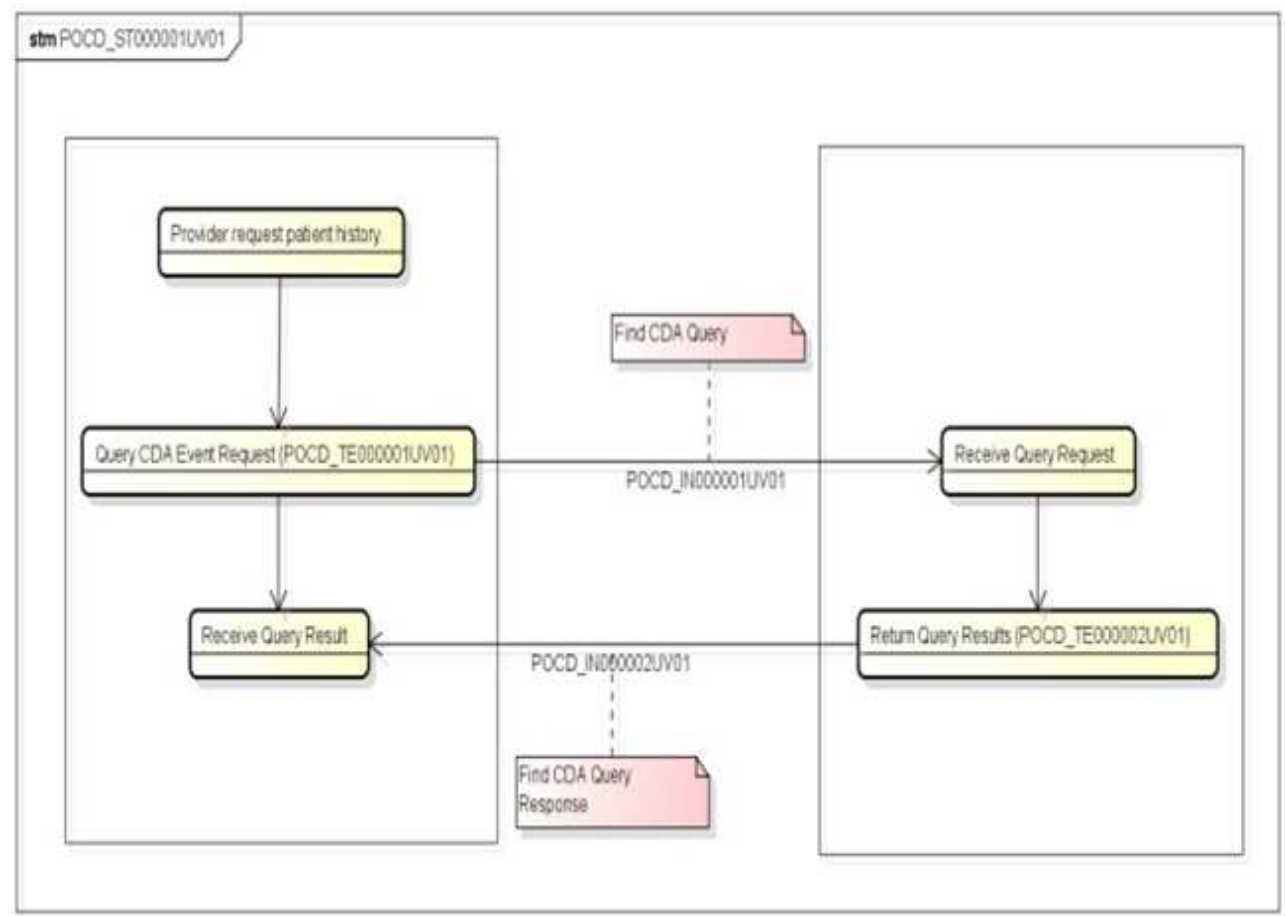

Figure 3: Analysis Scheme.

\section{CONCLUSIONS}

It was design and develop the message prototype for the transmission of a CDA between applications. In this process, it could be verified that is necessary the establishment of process and procedures, as well as the identification of other messages with which you can interoperate. In this sense, it was made a significant contribution to the solution of design and implementation of process for the HL7 message.

Validate the message of the prototype develop from a clinical simulated and standardize document applying the HL7 version 3 methodology, to check the validation in the international standard. It was built and it was proof that the message prototype for the transmission of a CDA, that achieve the necessary characteristics. The proof of the message was made in the MARELI platform in the FUNTELMED foundation, which has an open telemedicine system that is permanently building messages.

Making a prototype of guidance for the implementation of the prototype of message develop, that allows the implementation of the message in other systems and that interacts with the development, for the FUNTLMED, and that can be used as a guide for the creation of other messages

The structure of the work, allows the development of it, under a Systemic approach and representation of the reality oriented to the practice, which was approved for the Engineering foundation

The results of this investigation facilitate the continuity of the work, and is catalogue as a technological innovation work because they support the development of a standard, which is beginning to be implemented and adequate for Colombia. 


\section{ACKNOWLEDGMENTS}

The authors would like to thank the Universidad Distrital Francisco José de Caldas and the GITEM research group that supported the development and testing of the project.

\section{REFERENCES}

1. Villegas M., Villegas N., Tamura G. Aspectos claves en la definición y adopción de estándares de interoperabilidad electrónica de datos: El caso de HL7 en el área de la salud In: S\& T. Systems Engineering and Telematics Engineering Magazine, December, 2008: vol. 6. no 12, p. 43-59.

2. Cortes, Mario Enrique. Mensajería electrónica parte 1. [en línea] s.l. Noviembre, 2009 [citado en 2010-10] Disponible en línea $\langle$ http://www.datasalud.net/CDA_examples/laboratory/hl7_v3mssg_1_v1.pdf>

3. Congress of Colombia Law 100 of 1993: Creación del Sistema de Seguridad Social Integral. December 23 of 1993.

4. Tamura G., Villegas N., Portilla, F. Aspectos metodológicos del proceso de adopción del estándar HL7v3 en Colombia: la experiencia del Comité Técnico de Casos de Uso de Laboratorio Clínico. In: $S$ \& T. Systems Engineering and Telematics Engineering Magazine, December 2009. vol. 7. no. 14, p. 71-90.

5. Funtelmed. sistema piloto de telemedicina región Bogotá [Online]. July 30, 2010 [In 2010-11] Available on internet http://190.146.145.160/sptrb/>

6. HL7 Argentina. What is a HL7? [Online]. January 13, 2010 [In 2010-10] Available on internet < http://hl7.org.ar/index.php?option=com_content\&task=view\&id=19\&Itemid=142>

7. Pacheco A. standards [online]. México. July 2008 [In 2010-10] Available on internet <http://www.cenetec.salud.gob.mx/descargas/telemedicina/taller_directrices/estandares.pdf >

8. World wide web consortium (W3C) España Guía Breve de Tecnologías XML [Online]. January 2008. [In 2010-10] Available on internet http://www.w3c.es/divulgacion/guiasbreves/tecnologiasxml

9. Query Infrastructure [Online]. September 2008. [In 2011-04] Available on internet http://www.hl7.org/v3ballot/html/domains/uvqi/uvqi.html.

10. HL7 Messaging Components [Online]. September 2008. [In2011-04] Available on internet http://www.hl7.org/v3ballot/html/help/v3guide/v3guide.html\#v3msg

11. HL7 Version 3 Standard: Transport Specifications Overview [Online]. January 2005. [In 2011-04] Available on internet http://www.hl7.org/v3ballot/html/infrastructure/transport/transport-intro.html

12. HL7 Version 3 Standard: Transport Specification - Web Services Profile, Release 2 [Online]. January 2010. [In 2011-03] Available on internet. http://www.hl7.org/v3ballot/html/infrastructure/transport/transport-wsprofiles.html

13. Web Services Enablement for Healthcare HL7 Applications - Web Services Basic Profile Reference Implementation [Online]. August 2005. [In 2011-05] Available on internet http://msdn.microsoft.com/en-us/library/ms954603.aspx 